\title{
Mathematics in Engineering Education: a Review of the Recent Literature with a View towards Innovative Practices
}

\author{
Birgit Pepin ${ }^{1}$ (D) $\cdot$ Rolf Biehler $^{2}$ (D) $\cdot$ Ghislaine Gueudet $^{3}$ (D)
}

Accepted: 10 March 2021/ Published online: 1 April 2021

(C) The Author(s) 2021

\begin{abstract}
The aim of the special issue is to bring together important current international research on innovative teaching and learning practices in mathematics in engineering education, and to develop deeper understandings of the characteristics of current teaching and learning practices that can inform the design and implementation of future innovative practice. The focus of this review paper is to provide a state-of-the-art overview of this emerging field at the cross-roads between mathematics and engineering education, in addition to introducing the papers of this special issue. To guide this paper, we posed three review questions: (1) How can current (teaching/learning/study) practices of mathematics in engineering education be characterized with a view towards innovation?; (2) What are the 'resources' (cognitive, material, digital, social) used, and what are those that appear also well suited for innovative courses?; (3) What are promising innovative practices in mathematics in engineering education, and what are the implications for curriculum reform? Looking back across the studies we summarized in the review, we conclude that they are lagging behind the more fundamental changes that are happening in engineering education, whilst addressing selected aspects of innovative changes within the current system of engineering education. At the same time, the nine papers of this special issue contribute new perspectives for innovative practices in mathematics in engineering education, for a better understanding of current practices and for future research.
\end{abstract}

Keywords Mathematics in engineering education · Innovative teaching and learning practices $\cdot$ Resources $\cdot$ State-of-the-art literature review

Birgit Pepin

b.e.u.pepin@tue.nl

Extended author information available on the last page of the article 


\section{Introduction}

The aim of the Special Issue is to bring together important current international research on innovative teaching and learning practices in mathematics in engineering education, and to develop deeper understandings of the characteristics of current teaching and learning practices that can inform the design and implementation of future innovative practices.

The rationale for this Special Issue relates to the enormous changes in engineering education over the past decade (Graham, 2018), which have also affected mathematics education in engineering universities. Many engineering universities report on high drop-out rates in mathematics, which has prompted the university departments to offer transition courses (to bridge the move from school to university mathematics) or 'service courses' (e.g. courses integrated into the different engineering courses, tailored for the particular topic use and understanding). Moreover, the development of technology and digital resources has led to new possibilities for engineering work in which mathematically complex problems are solved with computer support, and visualizations and simulations play a central role (Enelund et al., 2011). These developments have also changed the conditions for teaching and learning. The new technologies make it possible to solve (beside special, simplified problems) also complex realistic problems and to visualize solutions, phenomena and theoretical aspects. New information technology also makes it possible for students (and instructors) to work at a distance, particularly in the recent pandemic. However, sustainable innovative changes have to be backed up by research. We observe a growing number of research studies on mathematics in and for engineering in recent years.

The focus of this paper is to provide a state-of-the-art overview of this emerging field at the cross-roads between mathematics and engineering education. We pose the following guiding questions for our review:

1. How can current (teaching/learning/study) practices of mathematics in engineering education be characterized with a view towards innovation?

2. What are the "resources" (cognitive, material, digital, social) used, and what are those that appear also well suited for innovative courses?

3. What are promising innovative practices in engineering education, and what are the implications for curriculum reform?

When we say "mathematics in engineering", we refer to mathematics as a service subject for engineering programs, usually taught by mathematicians, as well as mathematics as an integrated part of engineering sciences, where it constitutes specific practices with mathematics being more than just a language for engineers.

We contend that reviewing the existing research literature with a view towards informing and documenting promising innovative practices in engineering education is likely to support the identification of 'unknown territories' in mathematics education, as well as assist to link mathematics and engineering education more closely. The review aims at setting the stage for the contributions to this special issue, but it also has 
the broader aim to review the field in order to identify recent evolutions and needs for further research.

In terms of methods, we reviewed the research literature with respect to the three above mentioned guiding questions (e.g. keywords such as engineering education, mathematics in engineering, resources for learning/teaching mathematics, modelling, innovative practices), in the following research journals, books and proceedings: CERME proceedings ${ }^{1}$ (CERME 8-11); chapter about University Mathematics Education in the ERME book (Winsløw et al., 2018); IJRUME previous issues; European Journal of Engineering Education previous issues (1979-2020); INDRUM proceedings $^{2} 2016$ and 2018; INDRUM book (Durand-Guerrier et al., 2021); ICME Topical survey (Biza et al., 2016); Bessot and Ridgway (2002); and the SEFI proceedings ${ }^{3}$ of the mathematics working group (2002-2018), as well as the conference proceedings of the khdm conference (Göller et al., 2017). These were chosen from a range of engineering and STEM education journals, in our search for sources that were explicitly linked to mathematics in engineering education. We realize that the identified sources could be complemented with other general engineering education sources which contain articles on mathematics education. Nevertheless, we contend that the chosen sources allowed us to observe important evolutions related to the questions studied, and to identify issues for further research. In addition, we complemented the chosen ones with references found in the papers. This led to 140 papers, book chapters and proceedings in total, which we identified as particularly relevant for answering our review questions.

After this introduction, the following sections 2, 3, and 4 address each of the three review questions. In section 5 we offer an overview of the special issue's articles, and in section 6 the conclusions and insights gained from the review of the existing literature and the special issue papers.

\section{Current Teaching and Learning Practices of Mathematics in Engineering Education}

\section{Curricula: Mathematical Content, Competencies and Praxeologies}

In the following we refer to studies that investigated the issue of mathematics in curricula for engineering education. These studies often associate two questions: "What mathematics should be taught to future engineers?"; and "What mathematics is actually taught to future engineers?" Studies about these questions have existed for more than 30 years, however the early studies were often not research-based and rather discussed list of contents.

An early example of organizing a practitioners' discussion was the ICMI study 3, "Mathematics as a service subject" (Howson et al., 1988), where several chapters address mathematics for engineering students. They are mostly written by practitioners,

\footnotetext{
${ }^{1} \mathrm{https}: / /$ www.mathematik.uni-dortmund.de/ erme/index.php?slab=cerme-proceedings

${ }^{2}$ https://hal.archives-ouvertes.fr/INDRUM

${ }^{3} \mathrm{https}: / /$ www.sefi.be/?post_type=proceedings
} 
namely by mathematicians teaching to future engineers who draw on their experience and on discussions with colleagues from engineering.

In recent years, we see three new research strands that may influence future innovative practices:

- Widening the scope beyond debates in tertiary education institutions in that real engineering practices outside education are studied to identify the qualifications needed

- Rethinking curricula from the perspective of competencies

- Theoretical studies with a deeper analysis of current mathematical curricula in and for engineering, often using the Anthropological Theory of Didactics.

The first perspective leads to investigate the mathematics used by engineers at the workplace, following the seminal study by Kent and Noss (2003). This, indeed, can contribute to choose more relevant mathematics curricula for future engineers. We do not develop this perspective here, because is not addressed in this special issue.

A landmark work on conceptualizing the mathematical needs of future engineers in terms of content levels and in terms of competencies is provided by SEFI (2013). The group proposes a 'framework for mathematics curricula in engineering education', drawing on the work of Niss (2003) and Niss and Højgaard (2011), which aims at reconceptualizing mathematics education at tertiary level in general. They define mathematical competence as "the ability to understand, judge, do, and use mathematics in a variety of intra- and extra-mathematical contexts and situations in which mathematics plays or could play a role" (Niss, 2003 p. 120/121). They propose to construct curricula for future engineers also around competencies like "Thinking mathematically", "Reasoning", "Representing", "Communicating", "Mathematical Modelling" etc. Mathematical contents (concepts, properties, procedures) are identified at detailed levels but formulated as mathematical competencies. For example, a topic such as coordinate geometry at "core zero level" is formulated in terms of 16 different competencies/skills. Competencies and contents are also identified at more advanced levels 1,2 and 3. This work is an example of determining what mathematics should be taught to engineers through reaching consensus among international experts. The new achievement is the theoretical competency framework used to specify curriculum goals. However, the following issue remains: how to take the structure of mathematics as a discipline into account for designing a course content?

The third strand is linked with recent studies drawing on theoretical frameworks which allow a fine-grained analysis of the current mathematical practices. Some of these studies (e.g. Romo-Vazquez, 2009; Quéré, 2019; González-Martín \& HernandezGomes, 2018) use the framework of the Anthropological Theory of Didactics (ATD; Chevallard, 2006). Within this perspective, the engineering courses are an institution, and the mathematics courses for future engineers are another institution. In a given institution, the knowledge is present as 'praxeologies' (types of tasks, techniques to achieve them, technologies justifying the techniques and theories) which are shaped by the institution. The above-named studies evidence that the same mathematical object is associated with different praxeologies in different institutions. For example, in a course of mathematics the integral was associated with praxeologies with a strong theoretical component (as defined in ATD). At the same time, in a course on 'strength of material' 
the praxeologies surrounding the integral only required basic calculations and had no theoretical component (González-Martín \& Hernandez-Gomes, 2018). While the same mathematics concepts (e.g. 'integrals') can be present in both, they involve different praxeologies. Students meet different praxeologies related to the same concept, and this is likely to cause misunderstandings and conceptual difficulties. From a different theoretical point of view, Kortemeyer (2019), and Kortemeyer and Biehler (2017), studied the mathematical practice within courses on electrical engineering in a normative sense and in students' solution processes and written examinations. They investigated the mathematical skills that were required in first-year courses in electrical engineering. After analyzing exercises (from an electrical engineering examination), they introduced a theoretical approach consisting of three elements/concepts: a normative solution called "student-expert-solution", "low-inferent analyses" (for qualitative studies with students), and categorizations of written student solutions. The authors reconstructed the way mathematics was used in an integrated manner in courses on electrical engineering, which could not adequately be described as mathematical modelling, as it is usually conceptualized in mathematics education. The authors offered a different conceptualization of the mathematical praxeology in electrical engineering.

Theoretical considerations can also guide the design of innovations. For example, ATD offers a perspective for designing innovative practices, named 'Study and Research Paths'. We present these aspects in section 4.

\section{Instructors' Views on Mathematics for Engineers}

Some of the studies investigating the views of instructors concern instructors' expectations. They ask instructors to answer questions like: "What do you expect (in terms of mathematical knowledge and competencies) from engineering students?". The questions can focus on different stages in engineering studies: from novice students (in this case the question concern prerequisites) to students at the end of the training (in this case the question concerns knowledge and competencies that should be developed during the engineering studies). The question already discussed in 2.1 concerning the mathematics needed for engineering is addressed in these studies with a systematic empirical research concerning the attitudes of university teachers to overcome the status of exposed single opinions.

Deeken et al. (2020) asked instructors of German tertiary institutions who were teaching mathematics for engineers in a systematic Delphi study about prerequisites from students entering universities needed to be successful in engineering studies. A conceptualization of possible facets of mathematical knowledge and competences was the starting point of the empirical survey. "The participants identified 179 prerequisites addressing: (1) mathematical content, (2) mathematical processes, (3) views about the nature of mathematics, and (4) personal characteristics. For 140 of these prerequisites there was a consensus regarding their necessity among the university instructors." loc. cit., p. 23). Moreover, the instructors expected a mathematical flexibility from students, in terms of performing simple mathematical processes in unfamiliar situations, while complex reasoning and proving was only expected in familiar situations. The results are a relevant contribution to transition research and for re-designing school curricula or for 
creating preparatory bridging courses or support measures for students in their first study year.

Faulkner et al.'s (2019) study asked engineering faculty members about the mathematical skills, abilities or attitudes that they hoped students to learn in their mathematics courses beyond calculation skills. Underlying is the concern that the standard mathematics courses do not provide the mathematical prerequisites necessary for coping with requirements in engineering courses. The notion of 'mathematical maturity' was used as an open concept for conceptualizing these demands and investigating teachers' views. They observed that this mathematical maturity was linked with a high level of modelling competencies; an ability to manipulate symbolic expressions and graphics; and an ability to make a relevant use of computational tools. According to the engineering teachers, the actual abilities of students did not match these expectations. In particular, students' modelling skills were not developed enough, and the teachers associated this with students' epistemic beliefs about mathematics (i.e. 'mathematics is abstract' and disconnected from the real world), which according to the instructors originated from their introductory courses (where abstract mathematics were taught).

Whereas these studies contribute to the normative question of what mathematics is needed for engineering from the perspective of university instructors, other studies are concerned with a deeper understanding on how teachers implicitly shape mathematics in their everyday teaching practice. Indeed, in the case of engineering studies, instructors in the same institution can have very different backgrounds concerning particular mathematical content and its teaching and learning (e.g. Hernandes-Gomes \& González-Martín, 2016, Sabra, 2019). Using ATD and asking six instructors with different backgrounds (in terms of initial studies they followed) teaching Calculus in engineering courses, Hernandes-Gomes and González-Martín (2016) observed that these backgrounds shaped their personal relationship with mathematics, which influenced their teaching practices concerning important aspects like: the procedural vs conceptual approach to mathematics; the level of rigor and the role of proof; the type of exercises they chose; the use of computers. Features of teachers' practices were inferred from the teachers' interviews.

Views of the instructors can differ in terms of what kind of mathematical practices and how the relevant content should be taught to future engineers. These practices will vary from one instructor to another. Since students meet many instructors, this can cause difficulties for them to build a coherent web of knowledge, in particular regarding high-level mathematics. Therefore, a deeper understanding of the variability of different curricular practices is necessary for addressing innovation concerns.

\section{Student Views and Affect}

A deeper understanding of current practices should also include a focus on student views and affect. Research studies approach this from an analytical perspective to first better understand engineering students' views. Others approach it from an innovation perspective, as for the enhancement of mathematics in engineering education research needs to address student learning, including their study and learning behavior. We have decided to present the analytical perspective in this section, and the innovation perspective in section 4 . 


\section{(a) Student views concerning their understanding of mathematics}

Research on student learning difficulties with the standard university mathematical content (e.g. calculus, linear algebra, differential equations) has been reported on in the general research literature on tertiary mathematics education; this is also relevant for engineering students' mathematical learning. However, we cannot review this body of research knowledge here, but focus on studies that are specifically concerned with the specific situation of engineering students.

The aim of the study by Jablonka, et al. (2017) was to investigate the extent to which first-year engineering students enrolled in undergraduate mathematics courses were aware of changes in criteria of what counted as legitimate mathematical activity as, for instance, compared to school mathematics. Their theoretical approach is based on Bernstein's (1971) sociological theory of framing and classification of knowledge. In this respect, they are using an institutional approach as is done by ATD with however a different perspective. Their method was to present different texts to students asking about their relation to mathematical activity. Based on observations and interviews with 60 undergraduate students, they found that students focused on a considerably wide range of aspects of these texts by which they partly (mis)recognized the specificity of the mathematical discourse relevant in their university mathematics course. This can be considered as one source of their learning difficulties.

Other studies addressed various mathematical content areas and concepts, such as derivative (e.g. Bingolbali et al., 2007) and linear algebra (e.g. Rensaa, 2017). In the study by Bingolbali et al. (2007), first year mechanical engineering students' understandings of the concept of derivative were compared with those of mathematics students' understandings. Results suggested that by and large, Mechanical Engineering students conceived of the derivative in terms of rate of change (in physical contexts), while Mathematics students conceived of the derivative more in terms of tangent. Moreover, the authors interviewed a small number of the students with regard to their view of mathematics. It appeared that Mechanical Engineering (and not mathematics) students viewed mathematics as a tool and wanted application aspects of the derivative in their course (ibid). However, Wolf (2017) found a more differentiated picture in the cohort he studied. A majority of engineering students of the whole cohort he studied was "application-affine" with regard to applications in their mathematics courses and appreciated the inclusion of modelling examples, a minority was not (see 4.1. for more details).

In terms of content, Rensaa (2017) investigated engineering students' descriptions of their own learning approaches in a Linear Algebra course. Contrary to views that engineering students are mainly interested in mastering procedures, a majority part of their students also and partly even more appreciated conceptual understanding, whilst self-assessing whether they had gained that understanding by being able to solving relevant mathematical tasks. The author suggests that, in the course and in the final examinations, one should emphasize the connection between theory and task design. Tasks should offer opportunities to engage in conceptual arguments on the preferred premises of solving tasks to address these attitudes of the students. 


\section{(b) Identity formation and self-efficacy development}

One of the main obstacles for engineering students at the beginning of their study is mathematics. It has been assumed that difficulties with mathematics may lead to drop out in the early stages of study (Pampaka et al., 2016), and one of the factors appears to be that students develop an 'identity' as a learner of mathematics at the transition from school to university mathematics. Harris et al. (2015) conducted interviews with engineering students who experienced problems with mathematics during their transition through the first year in different program contexts. Results revealed how these students understood the relation between engineering and mathematics, and students mainly drew on mathematics for its 'use- and exchange-value'. At the same time, Kaspersen et al. (2017) measured engineering students' mathematical identities and related these measures to grades in university mathematics courses. They concluded that the mean average grade amongst students with high mathematical identities was significant, and about one grade higher than students with low mathematical identities. Moreover, they reported on a strong association between mathematical identity and average grade, but only when mathematical identities were high. It remains an open question how identity building can be fostered in order to better support students.

Self-efficacy (SE) in mathematics has often been associated with (mathematical) identity, and it has been shown to be positively related to undergraduate engineering students' achievements in examinations. In a study by Mamaril et al. (2016) SE measures were designed to assess the multifaceted skills required of engineers - this was said to improve the predictive relationship between efficacy beliefs and performance. Students' intrinsic value in engineering predicted their intentions to persist in the engineering profession. In terms of mathematics SE, Kürten (2017) investigated the SE of engineering students in the introductory phase of their studies. She focused on changes occurring in the first weeks, reasons for those changes, and the effects of a mathematics pre-university bridging course on SE. Based on results of interviews, she could show that students' mathematics and social SE rose during the pre-university bridging course, and that this effect was stable over a period of at least 3 months.

In sum, the studies of section 2.3 point to very different facets of students' views of mathematics, which would be relevant for a student-centered redesign of courses in mathematics: their understanding what constitutes a legitimate mathematical activity at university level, how conceptual and procedural understanding are related and relevant, a contextual interpretation of mathematical concepts (such as the derivative rate of change in contexts of co-variation in physics) and their attitudes about including the view that mathematics as a tool to solve engineering problems should be shown also in mathematics courses themselves. Moreover, the development of an identity as an engineer (rather than as a mathematician) and of self-efficacy can be relevant factors for innovative redesigns in the mathematics education of future engineers.

In addition to these insights from section 2.3, we have shown in 2.1. how efforts to overcome lists of contents in favor of rethinking curricula from the perspective of competencies, and deeper analyses of current mathematical praxeologies in the mathematics and the engineering course (using ATD), have helped to develop a new theorybased view of what mathematics should be taught to engineers. This view is enhanced by empirical studies of instructors' views (in 2.2.) of what students should bring as mathematical requisites to an engineering course and how one can conceptualize 
teachers' views of desired students' learning results beyond calculation skills. Moreover, studies showed how the mathematical content taught is also shaped differently by teachers without them being fully aware of these processes. These are relevant boundary conditions for designing innovative practices.

\section{Resources and Technology}

In this section we use the term 'resource' leaning on the work of Adler (2000): a 'resource' is anything likely to 're-source' the learning activity of engineering students. It encompasses material resources like textbooks or various educational technologies. But we also consider discussions with other students as social resources. A very large number of research studies concern the use of different kinds of technologies for future engineers. We firstly synthesize research concerning digital curricula (online courses etc.); secondly dedicated software (CAS, spreadsheet etc.); and thirdly studies focusing on diverse kinds of resources,

\section{Digital Curricula for Future Engineers}

Some aspects in the design of digital curricula for future engineers can be viewed as specific for engineering students: the heterogeneity (in terms of mathematics knowledge) of engineering students is known as very important, and the use of digital tools permits to take this into account. Caridade and Rasteiro (2016) used "Interactive Online Learning Modules" on a Moodle platform, offering resources and tools for self-directed learning and replacing the traditional lectures. In a pilot study (with 13 students), they observed a positive impact on students' results to a post-test (compared with a pre-test); nevertheless, most of them declare that they prefer traditional courses in presence. Weltman et al. (2019) studied the impact of using (to complement the course) an adaptive online tutorial, offering explanations, tools for self-evaluation etc. They observed that students using the online tutorial considered that it helped them to develop their understanding, and that their exam marks were higher than those of students who did not use the online tutorial.

From these studies, we understand that digital curricula are designed and tested, but often not based on a systematic instruction theory, and the evaluation methods are very diverse and isolated. This would call for a more systematic approach to design and integrate digital resources into an innovative curriculum. This has been started in general mathematics education (e.g. Documentation Approach to Didactics- DAD; e.g. Trouche et al., 2019) and curriculum theory (e.g. Voogt et al., 2015).

We note that we do not consider here that the mere use of digital curricula makes a teaching innovative. We observed that the informative (in terms of innovations) research results about digital curricula were linked with the use of these curricula in an innovative course format (e.g. flipped classrooms, Fredriksen et al., 2017). Concerning the use of a 'flipped classroom' approach, its main advantage (in terms of active student learning) is that any direct instruction could be reserved for out-ofclass videos. This provides the instructor with the freedom to facilitate activities in-class that focus on key concepts with groups of students. Fredriksen (2018) investigated the learning experiences of a group of first-year students in computer engineering in a 
flipped classroom setting. Results showed that students were able to utilize previous knowledge from the videos, in addition to other mediating means (in this case successfully creating a mathematical model of a simulated double Ferris wheel movement). However, there have also been voices that regard the flipped classroom as inappropriate, as earlier studies have indicated: apparently students perceive a disconnect between out-of-class components and in-class components, and that this may be enhanced by the flipped classroom model. The purpose of the paper by Tague and Czocher (2016) was to present students' perceptions of a more coherent flipped version of a Differential Equations course for engineering students. The course was designed to address cognitive obstacles and to reduce the potential disconnect between in-class and out-of-class activities. Students' perceptions of the course suggested that their model for flipped classroom design did circumvent many of the instructional problems reported in prior studies of flipped classrooms.

\section{Use of Specific Software}

Reviewing the literature considering the use of software in mathematics education for future engineers, we identified two issues:

1. Some studies consider digital tools and their use for mathematical problem solving as an essential new skill for future engineers, and ask which activities afford the learning of such new skills. This is a completely different perspective from using digital tools as a means to improve learning.

2. If we regard digital tools and their use as a way to enhance mathematical learning, we would ask questions concerning how technological tools could be integrated in courses for future engineers. The answer to this question depends on the kind of tool used, and on the aims of the course

With regard to (1), Van der Wal et al. (2017) have refined the concept of 'technomathematical literacies' (TmL), which had been introduced by Kent et al. (2005) to describe combinations of mathematical and IT competencies needed in technical workplaces. The engineering studies should contribute to the development of these competencies, but how? Van der Wal et al. (2019) observe that a project-based course using a rich technological environment associated with relevant teaching practices can contribute to this development. The students are invited to present and comment their use of software (e.g. calculation done with Excel), which is collectively discussed. The students develop a reflective use of the software, not limited to calculations, but also used for example to control the correctness of a solution. Indeed, there are a number of studies on how to integrate particular software into university mathematics education (e.g. CAS, Marshall et al., 2012, programming, Broley et al., 2018), but this knowledge has not been acknowledged in the literature on mathematics engineering education, as far as we know.

In their study, Dana-Picard and Steiner (2004) recommend the use of 'low-level' CAS commands in the teaching of mathematics for engineers, to promote understanding of the processes and avoid a 'black-box' effect. In this case the use of the tool in the course is purposefully different from the workplace use. At the same time, in statistics courses for engineers, working on questions linked with the engineering practice (with 
real data and statistics software) seemed to promote students' involvement and understanding (Quéré, 2019).

In terms of video and visualization enhanced learning, in a study by Howard et al. (2018) a mathematics module for non-mathematics specialists had been developed, where students were given the choice of completing the module content via short online videos, live lectures or a combination of both. The team investigated students' specific usage patterns with these resources. The main perceived advantages of lectures were the ability to engage in group tasks, to ask questions, and to learn 'gradually', whereas perceived benefits of videos included flexibility of scheduling and pace, and avoidance of large, long lectures. A very different use of visualization, that is learning through visualizing, was investigated in the study by Hogstad et al. (2016). Based on a framework for mathematical representations, visualizations and mediation, they studied engineering students' use of visualizations to communicate while solving mathematical problems with the visualization tool Sim2Bil (a simulation of two cars, velocity graphs, and an input for velocity functions).

\section{Engineering Students' Use of (Digital) Resources}

In this section we consider research studies concerning the use of resources (including digital resources) by engineering students, which is another way of looking at student learning strategies.

Kanwal (2020) observed the work of engineering students in a distant course using a digital learning environment (MyMathLab, MML). The environment offered different kinds of resources. She observed uses that can have negative consequences on the students' mathematical activity. Indeed the students, using Maxima, can find a correct numerical answer (validated by MML with a "right answer" feedback) even when they misunderstood the mathematics involved. The students know that the final assessment will also have this digital form, and that this kind of CAS use is enough to receive a good mark. Kanwal evidenced that designing appropriate tasks for engineering students working on a learning management system requires a precise analysis of the students' potential activity.

Kock and Pepin (2018) investigated the resources used by first year engineering students for their learning of Calculus and Linear Algebra. The notion of resources applied is more general than just digital resources. Students built on secondary school experiences and emulated school mathematics learning strategies into their university courses, where some subsequently experienced difficulties. They found that the course organization and the alignment of curriculum materials with the learning goals had an impact on the students' choice and use of resources. Particularly in larger courses, students should be better and more explicitly supported in their resource management. This is of particular relevance in first year university courses that require a very different resource management and integration from what the students were used to do at secondary level.

Concerning resources and digital technologies, the following aspects can be summarized from the studies evoked in this section: First, engineers in the workplace need to combine mathematics and digital technology, and the concept of technomathematical literacies (TmLs) is a major theoretical result from the recent literature capturing this fact. It permits a fine-grained analysis of the engineers' needs, and also 
the design of courses supporting the development of these TmLs. Using digital technologies or resources, to enhance engineering students' learning of mathematics is a second issue. Several studies have evidenced promising forms of usage, considering in particular the heterogeneity of the engineering students. Some of these promising uses take place in innovative courses (e.g. flipped classroom-based courses). Nevertheless, we note that the research results in mathematics education about specific software (e.g. CAS), or about the orchestration of digital resources, need more systematic research that could lead to results specific to the engineering education context. Third, an increasing number of studies concern the use of several types of resources (e.g. material, digital, social, cultural) by engineering students. They evidence that these students need to be supported in their choice and use of resources. More systematic studies, drawing on relevant theories about the potential of (digital) resources, of their actual use by engineering students, and of the consequences of this use in terms of learning, is a promising direction for future research.

\section{Promising Innovative Practices}

This section is divided into two parts: (4.1) tackles 'mathematical modelling' as an innovative practice; and (4.2) addresses other promising innovative teaching and learning practices.

\section{Mathematical Modelling as Innovative Practice}

We already mentioned the SEFI (2013) framework, viewing mathematical modelling as part of the competence framework for the mathematics education, based on work of Niss (2003). We will report on studies integrating mathematical modelling in an innovative way in the courses on mathematics education.

In a study by Abou-Hayt et al. (2019), the team investigated the integration of the methods of mathematical modelling and engineering designs in project work, and they concluded that this supported a deeper student understanding. Quite a few studies on mathematical modelling or integrating applications of mathematics in engineering education disciplines have used the ATD (or some aspects of it): for example, the study by Florensa et al. (2016) reported on the design process of a Study and Research Path (SRP) in a course on General Elasticity using mathematical modelling. They claimed that with the SRP design they could overcome the identified didactical problems (through the use of ATD) by proposing a possible new rationale for teaching General Elasticity. The design, implementation and evaluation of SRPs, in particular for future engineers, is increasingly studied by researchers (e.g. Siero et al., 2017, Quéré, 2019).

The earlier noted research and development project by Wolf (2017) had the aim to develop modelling tasks from the context of mechanical engineering, of a kind and size that they could be given as one of the four weekly homework tasks in a course on mathematics for engineering, which had traditionally been taught without any explicit reference to applications. The developed tasks (see Wolf \& Biehler, 2016) are based on theoretical criteria of suitability with regard to (among others) the mathematical context, the context of mechanical engineering, the modelling competence 
requirements, and the context of weekly tasks. Wolf (2017) showed positive evaluations by students and positive effects on their motivation to study mathematics, in particular for those students who considered themselves as affine to applications to mathematics. However, this was not the case with all students; some of them studied industrial engineering and were not primarily motivated by solving problems in mechanical engineering. The positive effect decreased in the second semester when the students became aware that modelling tasks were not part of the mathematics examinations.

Engineering students often fail to see the connection between the mathematical procedures they are expected to master and engineering applications. An innovative approach by Härterich et al. (2012) aimed at making these connections accessible by involving students in hands-on projects on modeling engineering problems, e.g. exploring an inverted pendulum as a model for the automated control within a Segway, utilizing differential equations, or trigonometric functions as ideal models for the oscillations involved when steering a crane. Providing both theoretical input and practical experiences, in combination with students presenting their results, proved to boost students' motivation and their views on the relevance of certain mathematical content, like eigenvalues or the Taylor expansion (see also Härterich \& Rooch, 2013, Rooch et al., 2016).

\section{Other Promising Innovative Teaching and Learning Practices}

Some of the studies on other innovative teaching and learning practices reported on measures for supporting students' learning processes at the systemic level, particularly in the transition from secondary to tertiary education. Other studies reported on innovative student-centered learning approaches, and again others focused on assessment.

\section{Secondary Tertiary Transition: Bridging and Remedial Courses}

In order to address students' lack of mathematical preparedness and motivation for university study (e.g. Hawkes \& Savage, 2000), many universities have established mathematics drop-in centers, or provided one-to-one support with specialist mathematics tutors. Many universities have created bridging courses for beginning engineering students that last from 2 to 6 weeks before the semester starts (see Bausch et al., 2014, for an overview, and Biehler et al., 2018 for an evaluation study of such courses in Germany). Treffert-Thomas (2017) conducted a longitudinal study with engineering students taking a (science) foundation course (to introduce them to knowledge needed for their engineering studies). The aim of the research was (a) to explore the reasons why students decided to take the foundation course, and (b) to explore students' mathematical progression into first year engineering and ultimately the usefulness of the foundation course. Results showed a variety of reasons for taking the foundation course, going beyond "because they did not have the necessary qualification for direct entry". This study also showed that students' mathematical progression was not linear; indeed, some strong and mathematically confident students reported struggling in their first-year engineering mathematics module. This raises the question about the appropriateness of the foundation course, also in terms of motivating students. Other studies 
(e.g. Greefrath et al., 2017) examined whether correlations could be established between the type of preparatory course, classroom-based or e-learning, and the examination results. Moreover, they were interested in to which extent it was possible to predict the course progress from test results at the start of the course. Fischer (2014) designed bridging courses with different versions for engineering students on the one hand and other students with mathematics courses on the other and shows the knowledge gain in these courses. However, the knowledge at the entrance into the course was a strong predictor of the success. Such bridging courses do not necessarily reduce the variability between the students' knowledge, which is often expected.

\section{Student-Centered Learning Approaches and Focus on Learning Strategies}

These approaches typically encourage students to develop their own learning trajectories, and modularized courses provide opportunities for students to weave their personal paths through the learning opportunities on offer, in order to reach their envisaged professional goals. For example, in the earlier noted study by Pepin and Kock (2019), the aim was to investigate which kinds of resources engineering students used in selected first year university mathematics courses (Calculus, Linear Algebra); and how they orchestrated them for their study of mathematics. Results showed that in the large Calculus course students followed various study paths, whereas in the smaller Linear Algebra course students could follow the study path established by the lecturer/ course designer, with all resources provided for students to pass their examinations. These findings resulted in the term Actual Student Study Path, to describe their selfreported ways of how they identified and orchestrated their chosen resources for their study of the mathematics. These study paths could be different for different students, and they were also depended on the course, and on the path and resources suggested by the lecturer.

In terms of innovative perspectives concerning learning strategies (that are likely to have an impact on students' achievement, e.g. Wild, 2005), we distinguish between cognitive learning strategies like strategies for elaborating a specific issue, metacognitive strategies like planning or monitoring the process of learning, or strategies to use resources like a specific learning environment. Investigating the issue of how to design teaching and learning procedures that impact positively on learning outcomes (e.g. examination success), Griese (2016) found that an interconnected collection of interventions focusing on learning strategies worked well: A weekly topic, e.g. notetaking, was addressed in the group meeting, in the mandatory helpdesk, on the elearning platform, in the workbooks, and by the mentors. Additionally, the students had to reflect on their experiences with different practices of note-taking in their learning logs. During the project phase of about 12 weeks, the personal support was gradually withdrawn, so that participating students were induced to learn how to rely on their own and their peers' resources.

Furthermore, the nature of the assignments involved appeared to have an impact on the learning practices employed by the students: When the questions were changed from multiple choice to open questions, Griese and Kallweit (2017) found, deep learning behavior gained impact. In their study to investigate engineering mathematics, Griese and Kallweit explored the relationship between learning behavior and examination outcome in first-year engineering courses. Their findings stressed the importance 
of making (continuous) effort, e.g. by processing the weekly assignments, and not getting distracted, whereas learning behavior related to understanding was found to have little relevance (Griese, 2016; Griese \& Kallweit, 2016). In addition, the importance of affective aspects of learning emerged in a multi-year Design Research project supporting engineering first years (Griese, 2016), as the lever to promote adequate learning behavior lies in motivating students to continuously pursue the learning strategies that have been found to have a positive influence on the learning outcome. Griese (2016) reasoned that for engineering students, the basic psychological needs, autonomy, competence, and relatedness, as described by Deci and Ryan (1990) in their self-determination theory, are to be considered when designing learning scenarios.

At the same time, Freeman et al. (2014) reported that active learning ${ }^{4}$ increases examination performance and that lecturing increased failure rates by $55 \%$. They claimed that these increases in achievement held across all of the STEM disciplines and occurred in all class sizes, course types, and course levels. According to their study, active learning was particularly beneficial in small classes and at increasing performance on concept inventories.

\section{Assessment Practices}

A widely used theoretical frame for studying assessment practices is that of Formative Assessment (FA). One of the main principles in FA is feedback to support the development of student self-regulation (Butler \& Winne, 1995), and FA encourages peer and self-assessment. In a study by Gaspar Martins (2018) a strategy to apply online weekly homework quizzes as formative assessment for engineering students was designed and tested in order to study if it increased student learning (in two courses). Results showed that students' adherence was very high, and that nearly all students referred to quizzes as fair and useful to learning. In more general terms, Trenholm et al. (2012) investigated fully-asynchronous online mathematics assessment and feedback practices. Results showed that assessment and feedback practices were "varied and complex": although richer assessment feedback appeared to be emphasized, evidence suggested that this feedback might not have been primarily directed at advancing student learning.

To summarize the main results in this section, we identified four themes. First, modelling appears to be one of the main areas of mathematics that speaks to engineers: it helps to make the mathematics relevant for engineering students, and it helps the sense-making of the engineering problem, and not stay at the level of 'calculating'. At the same time, it is perceived to be difficult (because after the sense making of the situation, the situation needs to be 'mathematised', that is put into mathematical language), and students often fail to see its value. Second, most innovative teaching and learning practices aim to empower the student for actively taking charge of their own learning (more than in traditional courses), becoming self-regulated, and developing their own study paths. Hence, these are all practices of a student-centered curriculum. Third, it appears that varying the learning strategies over the course worked well for students. In particular, open questions seemed to activate and engage students rather

\footnotetext{
${ }^{4}$ Active learning is a method of learning in which students are actively or experientially involved in the learning process and where there are different levels of active learning, depending on student involvement.
} 
than multiple choice questions, and active learning in turn increased attainment in examinations. Fourth, regarding assessment practices, formative assessment seemed to be beneficial for learning mathematics in engineering education, and feedback was one of the main components here, in particular feedback on tasks and the processes of solving the tasks. If innovative design does not go hand-in-hand with new assessment systems that reflect the new goals (constructive alignment), an innovation may not have a lasting effect (see also e.g., Borrego and Cutler, 2010).

\section{Papers of the Special Issue in the Context of Research on Mathematics in Engineering Education}

The nine papers of this special issue stand in the tradition of research we have identified in previous sections. We structure the papers for this special issue in the following way:

1. Bridging mathematics and engineering sciences: understanding and relating different praxeologies (four papers)

2. Designing, supporting and studying problem-based learning in mathematics for engineering (two papers)

3. Studies on innovative practices of Mathematical Modelling (two papers)

4. Analysis of institutional re-designs of mathematics curricula for engineering students (one paper)

In the following editorial paragraphs, we will introduce and frame the new research studies in more detail.

\section{Bridging Mathematics and Engineering Sciences: Understanding and Relating Different Praxeologies}

The first group of papers uses the Anthropological Theory of Didactics (ATD) as a theoretical basis and contributes as a whole to review questions 1 and 3 . They build on the praxeological analyses we have reviewed in section 2.1 and underline the scientific fertility of this approach for backing up innovative practices in various mathematical domains. Suggestions for innovative practices are based on a deeper analysis of the different praxeologies of mathematics for engineers, of mathematics in engineering, and in the workplace. Some of the papers focus on the analysis of different praxeologies (and extend the mathematical domains for which such analyses have been done). With these analyses, they lay the ground for future redesigns of curricula.

Rønning presents a praxeological analysis of the topic of Fourier series in a course on signal theory; this topic is typically introduced and used in mathematics and in electrical engineering. The analyses consist of a textbook analysis of one widely used textbook in mathematics for engineers, and the analyses of a textbook and lecture notes in signal theory. The aim of the analyses was to investigate possible differences in the motivation for introducing Fourier series in mathematics and in signal theory, as well as differences in the techniques (in the sense of ATD) used, and the justifications behind the techniques. 
Gonzalez-Martin conducted a praxeological analysis on how calculus was actually used in engineering programs. He analyses two courses (Strength of Materials, and Electricity and Magnetism) to examine their use of integrals. Results showed that integrals were used to introduce engineering notions in both courses, but that the uses and rationales presented were quite different from those seen in calculus course praxeologies. Moreover, integrals did not factor highly in students' assessments in either course, which seemed to imply that students might pass these courses without any knowledge of integrals as taught in their calculus courses.

The research by Hochmuth and Peters also focused on signal theory, albeit in a more comprehensive sense. They identified two institutional mathematical discourses; one related to higher mathematics for engineers, and one related to electrical engineering. By extending the theoretical approach of ATD by means of Weber's ideal types they can use this theoretical approach in analyzing students' solution to an exercise form signal theory and point out their relations to the different discourses. The authors see their analysis as relevant for enabling lecturers to make didactic decisions about whether or not to explicate various mathematical discourses that are effective in electrical engineering courses. Appropriate new didactic tools must still be developed on the basis of the research-related terms introduced in their paper in order to support an innovative practice.

Schmidt and Winsløw consider that a central problem in undergraduate mathematics education for future engineers consists in the perceived and actual relevance of the mathematical content. Their ATD-based analysis suggests solutions to this challenge based on longstanding development work. The notion of "authentic" problems of mathematics in engineering (APE) is made more precise and illustrated by examples. How such APE can be realized in teaching considering institutional and epistemological conditions (different praxeologies) is elaborated and exemplified in their paper. Special emphasis is also given to the use of digital resources (computer algebra systems) for supporting the realization.

\section{Designing, Supporting and Studying Problem-Based Learning in Mathematics for Engineering}

Whereas the ATD-based papers all focus on particular domains, the second group of papers focusses on problem-based learning in mathematics in general and are based on other theoretical foundations. They particularly consider which kind of resources are adequate for supporting student-centered learning and in this respect they build on the research we reviewed in section 3. The papers also include the critical issue of redesigning assessments that we pointed to at the end of section 4 .

Cook developed a practice-based engineering degree, in which students worked on real-world, team-based projects from day one and throughout the course. This course was designed to address the need for employability skills in a rapidly changing world. Teaching mathematics in this way required a very different approach to the lectureexam based model prevalent in most engineering degrees. In order to ensure all students developed the fundamental skills and knowledge required in engineering courses, a micro-credential-based curriculum was developed where micro-credentials were mapped to projects and delivered "just-in-time". The study also analyzed students' achievements. 
Pepin and Kock analyzed challenge-based learning contexts as innovative contexts for stimulating new types and new qualities of student learning. An essential question was which resources were used and could/should be provided to support students' learning and study paths in such innovative learning environments. They pointed to the implications for the professionalization of university instructors (who coached students through such courses/projects), and for the education of students who opted for such courses/projects: instructors have to be supported to develop as appropriate coaches in such complex environments; students have to be(come) self-directed learners, and need to be supported with challenged-based trained instructors or coaches, in addition to suitable curricular, technological, and social resources.

\section{Studies on Innovative Practices of Mathematical Modelling}

The third group is related on the research reviewed in section 4.1. and stand in the tradition of regarding mathematical modelling as a central topic that can contribute to engineering education by combining elements from mathematics and from engineering studies into self-regulated modelling activities. Modelling activities can be related to the workplace or to an engineering practicum. Offering courses on mathematical modelling can be seen as innovative in many institutions, in some of them there is a long-standing tradition. One of the two papers points to the relevance of technological resources for the modelling process (digital tools or a MOOC, see section 3) and thus responds to our second review question. The assessment of modelling competences and skills is a large issue in the general research on mathematical modelling in secondary and tertiary education. In a second paper, this topic is adapted to modelling courses for engineers and the developed assessment tools can support innovative practices in mathematical modelling. By this, it contributes to the issue of constructive alignment that we identified in section 4. Moreover, one of the papers explicitly addresses the crucial aspect of self-efficacy (see section 2.3.b), well integrated in the context of modelling.

The context of Czocher et al.' s paper was to use mathematical modelling as a topic in courses of mathematics for engineering, also to improve the relation between mathematics and its use in engineering contexts. The paper supports innovative practices of mathematical modelling in the sense that it suggests new tools to measure students' competences and self-efficacy, namely The Modeling Competency Questionnaire (MCQ) for assessing modeling competencies and the Mathematical Modeling Self-Efficacy Measure (MSE) targeting at self-efficacy for carrying out modeling competencies. The paper analyses the quality and the interrelation of the tools.

The research question of Merck et al. is based on an innovative teaching approach that has been continuously developed over 5 years: mathematical modelling skills were developed as part of an online course. In this respect, their study contributes to the question of how to adequately use digital resources (online courses and digital tools). The study analyses how students perceived mathematical modelling in the context of this online course. They found that: (a) the module allowed students to be a part of the modeling process, (b) using technology in the module helped them to understand what they were doing in mathematical modelling, (c) using technology in the module helped them to develop also a set of practical skills that are important in engineering practice at the workplace, and (d) difficulties with technology and/or the modeling decisions they 
had to make in the module activities were in some cases barriers that interfered with their ability to learn. The authors pointed to implication on how the use of digital tools should be integrated in modelling activities, in order to support deep learning instead of stimulating a mechanical use of black box models.

\section{Analysis of Institutional Re-Designs of Mathematics Curricula for Engineering Students}

The third review question "What are promising innovations/innovative practices in engineering education" is systematically analyzed by the paper in the fourth 'group' of papers by a case study of comparing two universities, where the calculus for engineer as an innovative had only been maintained in one of the institutions. Identifying the responsible factors can inform future curriculum innovations. This institutional comparison is a fertile new contribution to the field.

The team addressed the following research questions: How did students' experiences of the engineering calculus course compare to their peer's experience of the regular calculus course? What motivated the decision to change the first-year calculus course for engineers? What was the evolution or sustainment of this curricular change? What factors may account for this curricular change being sustained or not sustained? The analysis showed a complex bundle of success factors, reaching from a interdepartmental coordinator embedded and respected in the relevant institutions, professional development of instructors, measurable success indicators and course content that took into account previous knowledge and also deficiencies. Designing a specific variation of the content was necessary but far from sufficient. A larger and sustained curricular change would rely on communication, monitoring, and shared vision amongst stakeholders.

\section{Conclusions}

\section{Summary of Review Results}

In this sub-section we present our answers to the review questions that guided our review study. The review questions were the following:

1. How can current (teaching/learning/study) practices of mathematics in engineering education be characterized with a view towards innovation?

2. What are the "resources" (cognitive, material, digital, social) used, and what are those that appear also well suited for innovative courses?

3. What are promising innovative practices in engineering education, and what are the implications for curriculum reform?

To 1 Historically, there has been an evolution in the literature about mathematics curricula in engineering education. At first, there were personal reflections by mathematicians on teaching mathematics to engineers (e.g. ICMI 3). Subsequently, scientific research studies developed progressively, using appropriate theories and methods, amongst them ATD, which provided a deeper analysis of current mathematical 
curricula in engineering. Another theoretical notion that is likely to inform teaching interventions is that of 'techno-mathematical literacy', originally started by Kent and Noss (2003) and further developed by Van der Wal et al. (2019). Studies about student practices evidenced in particular that interventions focusing on learning strategies can have a positive impact on engineering students' achievement. We observed that the current practices of instructors have not yet been comprehensively investigated; this could be an interesting direction for future research likely to inform the design of innovations.

To 2 The field of resources, in particular digital curriculum resources, has probably developed most over the past decade. With digitalization and the emergence of a huge amount of open educational resources, students and instructors have access to and can choose from an enormous amount of digital resources. University instructors have also changed their course materials to be digitally available, and students can access the digital resources wherever they are (e.g. at home, in the train). Moreover, students can prepare for course modules, go through and orchestrate the curriculum resources in line with their individual learning and study paths, and at their own rhythm. This means that course designers of mathematics for engineers have to shift mindset, from instructororiented ('this is the mathematics and the practices you need') to student-centered ('which mathematics modules do I (as a student) need and for which purpose'). In other words, it is not clear to what extent teaching and (expected) learning approaches have been adjusted to these new digital environments, where new and different interactions are appropriate and can be anticipated. Nevertheless, most of the existing studies concerning the use of resources by engineering students do not seem specific for the engineering context (except the works on 'techno-mathematical literacies'). Hence, we consider that more research is needed about what a relevant choice and use of resources by engineering students and by their instructors could be.

To 3 From our review, we identified four themes that appear to address the question: (a) Modelling was seen as an innovative practice, as it seems to be close to and useful for engineering practices (e.g., conceiving and designing models, trialing them out and checking against reality, etc.). (b) Active student learning on open-ended real-life tasks and self-regulation are the main ingredients of a second group of innovative practices. Here, students develop their own learning trajectories, in order to overcome a 'compartmentalized curriculum' and atomistic approaches to learning. (c) In line with new innovative teaching and learning practices, assessment practices also changed, to include more formative practices and iterative feedback loops. (d) In order to prepare students for the mathematics in engineering education and to forego the high drop-out rates, many pre-university "bridging" courses were initiated introducing pre-first-year students to the 'new' mathematics that expects them in the first year, and in this way attempting to bridge the gap between school and university mathematics. The implications for curriculum reform are the following: The mathematical competencies in and for engineering are developed by working on real-life professional tasks/problems/ challenges (rather than on mathematical topic areas that might or might not be used later in projects), with support and guidance from the instructor. The curriculum design involves the development or identification of complex learning tasks/challenges and their 'monitoring' (in terms of assessment of student learning), in addition to the 
provision of an infrastructure (for instructors and students) to work in such innovative environments.

\section{Future Perspectives for Innovative Mathematics Education for Engineers}

Promising innovative approaches to teaching and learning mathematics in and for engineering education have emerged in various places, but it is not clear to what extent these strategies (a) are coherent and effective (e.g. for different learning environments or disciplines); (b) can be scaled up/down (e.g. larger/smaller courses) and across the years; (c) are practically possible (e.g. with the digital resources available); (d) fit within the present curriculum structures (in line with present goals and assessment strategies); and (e) are relevant for engineering students of different engineering disciplines. Studies into these aspects would be necessary, in order to convince educators and policy makers to introduce innovative practices of mathematics teaching and learning in/for engineering education.

Moreover, in such innovative environments the university has to consider the following:

1. Mathematics lecturers cannot (and should not) only draw on their own experiences of teaching and learning (in traditional ways), but should be encouraged to ask: what means 'hands-on' or 'challenged-based' learning in mathematics education (in such engineering courses), and how can I design, teach and assess such learning? How can I use (or design) educational technology and digital resources usefully and beneficially for enhanced student engagement and learning? To design for and enact these considerations needs time and resources, and support from the institution/university.

2. Future students may not come for lectures to the campus, but for working in innovation/maker spaces, together with their peers, and the mathematics is expected to be learnt with a variety of devices (including e.g. ipads; mobile phones) mobile learning of mathematics, on or off campus, is likely to require different modes of engagement and learning paths than traditionally envisaged.

3. Traditionally, mathematics education has been expected to provide the prerequisite knowledge for the engineering curriculum, because it has been said to lay the foundation for basic mathematical knowledge as well as for good analytical and problem-solving skills often required in traditional engineering work. More recently, and with the advent of digital technology, the following goal for mathematics in and for engineering education is of growing importance (Filho \& Nesbit 2016): the ability to interpret the meaning of mathematics in engineering. This is particularly significant in the use of computer software applications. Particular applications (e.g. Engineering design ${ }^{5}$ ) offer approaches that foster and support students' development of their problem-solving abilities. Digital resources and educational technology (e.g. virtual reality) can make such problems solving

\footnotetext{
${ }^{5}$ Engineering design is the method that engineers use to identify and solve problems. It has been described and mapped out in many ways, and all descriptions include some common attributes. Engineering design is a process and powerful approach to problem solving.
} 
authentic. In this sense, mathematics evolves from being a tool, to also becoming an inspiration for engineers, as it offers mathematical structures that become potential solutions to engineering problems.

Open Access This article is licensed under a Creative Commons Attribution 4.0 International License, which permits use, sharing, adaptation, distribution and reproduction in any medium or format, as long as you give appropriate credit to the original author(s) and the source, provide a link to the Creative Commons licence, and indicate if changes were made. The images or other third party material in this article are included in the article's Creative Commons licence, unless indicated otherwise in a credit line to the material. If material is not included in the article's Creative Commons licence and your intended use is not permitted by statutory regulation or exceeds the permitted use, you will need to obtain permission directly from the copyright holder. To view a copy of this licence, visit http://creativecommons.org/licenses/by/4.0/.

\section{References}

Abou-Hayt, M., Dahl, B., \& Rump, C. (2019). Integrating the methods of mathematical modelling and engineering design in projects. In U. T. Jankvist, M. Van den Heuvel-Panhuizen, \& M. Veldhuis (Eds.) Proceedings of the eleventh congress of the European society for research in mathematics education (pp. 4729-4736). Utrecht, The Netherlands: Freudenthal Group \& Freudenthal Institute, Utrecht University and ERME.

Adler, J. (2000). Conceptualising resources as a theme for teacher education. Journal of Mathematics Teacher Education, 3, 205-224.

Bausch, I., Biehler, R., Bruder, R., Fischer, P. R., Hochmuth, R., Koepf, W., Schreiber, S., \& Wassong, T. (Eds.). (2014). Mathematische Brückenkurse: Konzepte, Probleme und Perspektiven. Wiesbaden: Springer Spektrum

Bernstein, B. (1971). On the classification and framing of educational knowledge. In M. F. D. Young (Ed.), Knowledge and control (pp. 47-69). London: Collier- Macmillan Publishers.

Bessot, A. \& Ridgway, J. (Eds.) (2002). Education for mathematics in the workplace. Dordrecht: Kluwer Academic Publishers.

Biehler, R., Lankeit, E., Neuhaus, S., Hochmuth, R., Kuklinski, C., Leis, E., Liebendörfer, M., Schaper, N., \& Schürmann, M. (2018). Different goals for pre-university mathematical bridging courses - comparative evaluations, instruments and selected results. In V. Durand-Guerrier, R. Hochmuth, S. Goodchild, \& N. M. Hogstad (Eds.), PROCEEDINGS of INDRUM 2018 second conference of the international network for didactic research in university mathematics (pp. 467-476). Kristiansand, Norway. https:// indrum2018.sciencesconf.org/data/Indrum2018Proceedings.pdf

Bingolbali, E., Monaghan, J., \& Roper, T. (2007). Engineering students' conceptions of the derivative and some implications for their mathematical education. International Journal of Mathematical Education in Science and Technology, 38(6), 763-777.

Biza, I., Giraldo, V., Hochmuth, R., Khakbaz, A., \& Rasmussen, C. (2016). Research on teaching and learning mathematics at the tertiary level: State-ofthe-art and looking ahead. ICME-13 topical surveys. Switzerland: Springer International Publishing AG.

Borrego, M., \& Cutler, S. (2010). Constructive alignment of interdisciplinary graduate curriculum in engineering and science: An analysis of successful IGERT proposals. Journal of Engineering Education, (4), 355-369.

Broley, L., Caron, F., \& Saint-Aubin, Y. (2018). Levels of programming in mathematical research and university mathematics education. International Journal of Research in Undergraduate Mathematics Education, 4(1), 33-55.

Butler, D. L., \& Winne, P. H. (1995). Feedback and self-regulated learning: A theoretical synthesis. Review of Educational Research, 65(3), 245-281.

Caridade, C.M., \& Rastero, D. (2016). Lesson Moodle for a self-directed learning of mathematics. Proceedings of the 18th SEFI mathematics working group seminar on mathematics in engineering education, (pp. 69-75). European Society for Engineering Education (SEFI), Brussels.

Chevallard, Y. (2006). Steps towards a new epistemology in mathematics education. In M. Bosch (Ed.) Proceedings of the IVth conference of the European society for research in mathematics education, (pp 22-30), Barcelona, Spain. 
Dana-Picard, T., \& Steiner, J. (2004). The importance of 'low-level' CAS commands in teaching engineering mathematics. European Journal of Engineering Education, 29(1), 139-146.

Deci, E. L., \& Ryan, R. M. (1990). Intrinsic motivation and self-determination in human behavior (3rd ed.). New York: Plenum Press.

Deeken, C., Neumann, I., \& Heinze, A. (2020). Mathematical prerequisites for STEM programs : What do university instructors expect from new STEM undergraduates? International Journal of Research in Undergraduate Mathematics Education, 6(1), 23-41.

Durand-Guerrier, V., Hochmuth, R., Nardi, E., \& Winsløw, C. (Éds.). (2021). Research and development in university mathematics education: Overview produced by the international network for research on didactics of university mathematics. Routledge.

Enelund, M., Larsson, S., \& Malmquist, J. (2011). Integration of a computational mathematics education in the mechanical engineering curriculum. Proceedings of the 7th international CDIO conference. Technical University of Denmark, Copenhagen, June 20-23.

Faulkner, B., Earl, K., \& Herman, G. (2019). Mathematical maturity for engineering students. International Journal of Research in Undergraduate Mathematics Education, 5(1), 97-128.

Filho, W. L., \& Nesbit, S. (Eds.). (2016). New developments in engineering education for sustainable development. Zuerich, Switzerland: Springer International Educational Publishing.

Fischer, P. (2014). Mathematische Vorkurse im Blended Learning Format - Konstruktion, Implementation und wissenschaftliche Evaluation. Wiesbaden: Springer Spektrum.

Florensa, I., Bosch, M., Gascon, J., \& Mata, M. (2016). SRP design in an elasticity course: The role of mathematics modelling. In E. Nardi, C. Winslow, \& T. Hausberger (Eds.), Proceedings of the second conference of the international network for didactic research in university mathematics (pp. 191-200). Montpellier, France: University of Montpellier and INDRUM.

Fredriksen, H. (2018). Analysing tasks for the flipped classroom from the perspective of realistic mathematics education. In N. M. Hogstad, V. Durand-Guerrier, S. Goodchild, \& R. Hochmuth (Eds.), Proceedings of the second conference of the international network for didactic research in university mathematics (pp. 296-305). Kristiansand, Norway: University of Agder and INDRUM.

Fredriksen, H., Hadjerrouit, S., Monaghan, J., \& Rensaa, J. R. (2017). Exploring tensions in a mathematical course for engineers utilizing a flipped classroom approach. In T. Dooley \& G. Gueudet (Eds.), Proceedings of the tenth congress of the European mathematical society for research in mathematics education (pp. 2057-2064). Dublin, Ireland: DCU Institute of Education and ERME.

Freeman, S., Eddy, S. L., McDonough, M., Smith, M. K., Okoroafor, N., Jordt, H., \& Wenderoth, M. P. (2014). Active learning increases student performance in science, engineering, and mathematics. Proceedings of the National Academy of Sciences, 111(23), 8410-8415.

Gaspar Martins, S. (2018). Weekly homework quizzes as formative assessment for engineering students are a fair and effective strategy to increase learning? In N. M. Hogstad, V. Durand-Guerrier, S. Goodchild, \& R. Hochmuth (Eds.), Proceedings of the second conference of the international network for didactic research in university mathematics (pp. 105-114). Kristiansand, Norway: University of Agder and INDRUM.

Göller, R., Biehler, R., Hochmuth, R., \& Rück, H.-G. (Eds.). (2017). Didactics of mathematics in higher education as a scientific discipline - conference proceedings. Universitätsbibliothek Kassel: http://nbnresolving.de/urn:nbn:de:hebis:34-2016041950121.

González-Martín, A. S., \& Hernandes-Gomes, G. (2018). The use of integrals in mechanics of materials textbooks for engineering students: The case of the first moment of an area. In N. M. Hogstad, V. DurandGuerrier, S. Goodchild, \& R. Hochmuth (Eds.), Proceedings of the second conference of the international network for didactic research in university mathematics (pp. 115-124). Kristiansand, Norway: University of Agder and INDRUM.

Graham, R. (2018). The global state-of-the-art in engineering education. Cambridge, MA: Massachusetts Institute of Technology (MIT).

Greefrath, G., Koepf, W., \& Neugebauer, C. (2017). Is there a link between preparatory course attendance and academic success? A case study of degree programmes in electrical engineering and computer science. International Journal of Research in Undergraduate Mathematics Education, 3(1), 143-167.

Griese, B. (2016). Learning strategies in engineering mathematics - conceptualisation, development, and evaluation of $M P^{2}$-Mathe/Plus (dissertation). Bochum: Ruhr-Universität Retrieved from https://hss-opus. ub.ruhr-uni-bochum.de/opus4/frontdoor/index/index/docId/4997.

Griese, B., \& Kallweit, M. (2016). Lernverhalten und Klausurerfolg in der Ingenieurmathematik Selbsteinschätzung und Dozentensicht. In Institut für Mathematik und Informatik Heidelberg (Ed.), Beiträge zum Mathematikunterricht 2016. Münster: WTM. 
Griese, B., \& Kallweit, M. (2017). Engineering mathematics between competence and calculation. In T. Dooley \& G. Gueudet (Eds.), Proceedings of the tenth congress of the European mathematical society for research in mathematics education (pp. 2129-2136). Dublin, Ireland: DCU Institute of Education and ERME.

Harris, D., Black, L., Hernandez-Martinez, P., Pepin, B., Williams, J., \& TransMaths Team. (2015). Mathematics and its value for engineering students: What are the implications for teaching? International Journal of Mathematical Education in Science and Technology, 46(3), 321-336.

Härterich, J., \& Rooch, A. (Eds.). (2013). Das Mathe-Praxis-Buch - Wie Ingenieure Mathematik anwenden: Projekte für die Bachelor-Phase. Wiesbaden: Springer Vieweg.

Härterich, J., Kiss, C., Rooch, A., Mönnigmann, M., Schulze Darup, M., \& Span, R. (2012). MathePraxis connecting first-year mathematics with engineering applications. European Journal of Engineering Education, 37(3), 255-266.

Hawkes, T., \& Savage, M. (2000). Measuring the mathematics problem. London: Engineering Council.

Hernandes-Gomes, G., \& Gonzales-Martin, A. (2016). Teaching Calculus in engineering courses. Different backgrounds, different personal relationships? In E. Nardi, C. Winsløw, \& T. Hausberger (Eds.), Proceedings of the second conference of the international network for didactic research in university mathematics (pp. 201-210). Montpellier, France: University of Montpellier and INDRUM.

Hogstad, N. M., Isabwe, G. M. N., \& Vos, P. (2016). Engineering students' use of visualizations to communicate about representations and applications in a technological environment. In E. Nardi, C. Winslow, \& T. Hausberger (Eds.), Proceedings of INDRUM 2016 (pp. 211-220). Montpellier, France: University of Montpellier and INDRUM.

Howard, E., Meehan, M., \& Parnell, A. (2018). Live lectures or online videos: Students' resource choices in a first-year university mathematics module. International Journal of Mathematical Education in Science and Technology, 49(4), 530-553.

Howson, A. G., Kahane, J.-P., Lauginie, P., \& de Turckheim, E. (1988). Mathematics as a service subject. ICMI studies. Cambridge: Cambridge books.

Jablonka, E., Ashjari, H., \& Bergsten, C. (2017). "Much palaver about greater than zero and such stuff” - first year engineering students' recognition of university mathematics. International Journal of Research in Undergraduate Mathematics Education, 3(1), 69-107.

Kanwal, S. (2020). Exploring affordances of an online environment : A case-study of electronics engineering undergraduate students' activity in mathematics. International Journal of Research in Undergraduate Mathematics Education, 6(1), 42-64.

Kaspersen, E., Pepin, B., \& Sikko, S. A. (2017). The association between engineering students' self- reported mathematical identities and average grades in mathematics courses. In T. Dooley \& G. Gueudet (Eds.), Proceedings of the tenth congress of the European mathematical society for research in mathematics education (pp. 22137-22144). Dublin, Ireland: DCU Institute of Education and ERME.

Kent, P., \& Noss, R. (2003). Mathematics in the university education of engineers. London: The Ove Arup Foundation.

Kent, P., Bakker, A., Hoyles, C., \& Noss, R. (2005). Techno-mathematical literacies in the workplace. MSOR Connections, 5(1), 1-3.

Kock, Z.-J., \& Pepin, B. (2018). Student use of resources in calculus and linear algebra. In N. M. Hogstad, V. Durand-Guerrier, S. Goodchild, \& R. Hochmuth (Eds.), Proceedings of the second conference of the international network for didactic research in university mathematics (pp. 336-345). Kristiansand, Norway: University of Agder and INDRUM.

Kortemeyer, J. (2019). Mathematische Kompetenzen in Ingenieur-Grundlagenfächern : Analysen zu exemplarischen Aufgaben aus dem ersten Jahr in der Elektrotechnik. Wiesbaden: Springer Spektrum.

Kortemeyer, J., \& Biehler, R. (2017). The interface between mathematics and engineering - problem solving processes for an exercise on oscillating circuits using ordinary differential equations. In T. Dooley \& G. Gueudet (Eds.), Proceedings of the tenth congress of the European mathematical society for research in mathematics education (pp. 2153-2160). Dublin, Ireland: DCU Institute of Education and ERME.

Kürten, R. (2017). Self-efficacy of engineering students in the introductory phase of studies. In T. Dooley \& G. Gueudet (Eds.), Proceedings of the tenth congress of the European mathematical society for research in mathematics education (pp. 2161-2168). Dublin, Ireland: DCU Institute of Education and ERME.

Mamaril, N., Usher, E. L., David Ross Economy., Li, C. (2016). Measuring undergraduate students' engineering self-efficacy: A validation study. Journal of Engineering Education, 105(2), 366-395.

Marshall, N., Buteau, C., Jarvis, D. H., \& Lavicza, Z. (2012). Do mathematicians integrate computer algebra systems in university teaching? Comparing a literature review to an international survey study. Computers \& Education, 58(1), 423-434. https://doi.org/10.1016/j.compedu.2011.08.020. 
Niss, M. (2003). Mathematical competencies and the learning of mathematics: The Danish KOM project. In A. Gagatsis \& S. Papastravidis (Eds.), 3rd Mediterranean conference on mathematics education (pp. 115-124). Athens, Greece: Hellenic Mathematical Society and Cyprus Mathematical Society.

Niss, M., \& Højgaard, T. (Eds.). (2011). Competencies and mathematical learning: Ideas and inspiration for the development of mathematics teaching and learning in Denmark. Roskilde University, IMFUFA.

Pampaka, M., Pepin, B., \& Sikko, S. A. (2016). Supporting or alienating students during their transition to higher education: Mathematically relevant trajectories in two educational contexts. International Journal of Educational Research, 79, 240-257.

Pepin, B., \& Kock, Z.-J. (2019). Towards a better understanding of engineering students use and orchestration of resources: Actual student study paths. In U. T. Jankvist, M. Van den Heuvel-Panhuizen, \& M. Veldhuis (Eds.), Proceedings of the eleventh congress of the European society for research in mathematics education (pp. 2614-2621). Utrecht, The Netherlands: Freudenthal Group \& Freudenthal Institute, Utrecht University and ERME.

Quéré, P.-Q. (2019). Les mathématiques dans la formation des ingénieurs et sur leur lieu de travail : études et propositions (cas de la France). Thèse de l'Université de Bretagne occidentale. https://hal.archivesouvertes.fr/tel-02281937

Rensaa, J.-R. (2017). Approaches to learning of linear algebra among engineering students. In T. Dooley \& G. Gueudet (Eds.), Proceedings of the tenth congress of the European mathematical society for research in mathematics education (pp. 2241-2249). Dublin, Ireland: DCU Institute of Education and ERME.

Romo-Vazquez, A. (2009). La formation mathematique des futurs ingenieurs. Paris: Thèse de 1'Université Paris VII.

Rooch, A., Junker, P., Härterich, J., \& Hackl, K. (2016). Linking mathematics with engineering applications at an early stage - implementation, experimental set-up and evaluation of a pilot project. European Journal of Engineering Education, 41(2), 172-191.

Sabra, H. (2019). The connectivity in resources for student-engineers: The case of resources for teaching sequences. In U. T. Jankvist, M. Van den Heuvel-Panhuizen, \& M. Veldhuis (Eds.), Proceedings of the eleventh congress of the European society for research in mathematics education (pp. 2644-2653). Utrecht, The Netherlands: Freudenthal Group \& Freudenthal Institute, Utrecht University and ERME.

SEFI. (2013). A framework for mathematics curricula in engineering education. Brussels: Brussels: European Society for Engineering Education (SEFI).

Siero, L., Romo, A., \& Abundez, A. (2017). Methodology for designing didactical activities as an engineering project of a tactile sensorial therapeutic ramp. In T. Dooley \& G. Gueudet (Eds.), Proceedings of the tenth congress of the European mathematical society for research in mathematics education (pp. 1004-1011). Dublin, Ireland: DCU Institute of Education and ERME.

Tague, J., \& Czocher, J. (2016). A theoretical approach to ensuring instructional and curricular coherence in the flipped classroom model of a differential equations course. International Journal of Research in Undergraduate Mathematics Education, 2(2), 223-245.

Treffert-Thomas, S. (2017). Getting into university: From foundation to first year engineering. In T. Dooley \& G. Gueudet (Eds.), Proceedings of the tenth congress of the European mathematical society for research in mathematics education (pp. 2322-2323). Dublin, Ireland: DCU Institute of Education and ERME.

Trenholm, S., Alcock, L., \& Robinson, C. L. (2012). Mathematics lecturing in the digital age. International Journal of Mathematical Education in Science and Technology, 43(6), 703-716.

Trouche, L., Gueudet, G., \& Pepin, B. (2019). The "resource" approach to mathematics education. New York: Springer.

Van der Wal, N. J., Bakker, A., \& Drijvers, P. (2017). Which techno-mathematical literacies are essential for future engineers? International Journal of Science and Mathematics Education, 15(S1), 87-104.

Van der Wal, N. J., Bakker, A., \& Drijvers, P. (2019). Teaching strategies to foster techno-mathematical literacies in an innovative mathematics course for future engineers. ZDM-Mathematics Education, 51(6), 885-897.

Voogt, J., Laferrière, T., Breuleux, A., Itow, R., Hickey, D., \& McKenney, S. (2015). Collaborative design as a form of professional development. Instructional Science, 43(2), 259-282. https://doi.org/10.1007/ s11251-014-9340-7.

Weltman, H., Hunter, L., Yannoulatos, S., Furfari, S. \& Marcus, N. (2019). Adapting Teaching and Learning: The Role Adaptive Tutorials Played in Supporting a Flipped-Style Chemistry Course. In G. Marks (Ed.), Proceedings of Global Learn 2019-Global Conference on Learning and Technology (pp. 208-213). Princeton-Mercer, New Jersey: Association for the Advancement of Computing in Education (AACE). Retrieved from https://www.learntechlib.org/primary/p/210307/. Accessed 31 Mar 2021.

Wild, K.-P. (2005). Individuelle Lernstrategien von Studierenden. Konsequenzen für die Hochschuldidaktik und die Hochschullehre. Beiträge zur Lehrerinnen- und Lehrerbildung, 23(2), 191-206. 
Winsløw, C., Gueudet, G., Hochmuth, R., \& Nardi, E. (2018). Research on university mathematics education. In T. Dreyfus, M. Artigue, D. Potari, S. Prediger, \& K. Ruthven (Eds.), Developing research in mathematics education: Twenty years of communication, cooperation and collaboration in Europe (pp. 82-96). London: Routledge (ERME series inaugural volume).

Wolf, P. (2017). Anwendungsorientierte Aufgaben für Mathematikveranstaltungen der Ingenieurstudiengänge - Konzeptgeleitete Entwicklung und Erprobung am Beispiel des Maschinenbaustudiengangs im ersten Studienjahr. Wiesbaden: Springer Spektrum.

Wolf, P., \& Biehler, R. (2016). Anwendungsorientierte Aufgaben für die Erstsemester-MathematikVeranstaltungen im Maschinenbaustudium (V.2). khdm-Report: Nr. 04-16. Quelle: http://nbn-resolving. de/urn:nbn:de:hebis:34-2016010549550.

Publisher's Note Springer Nature remains neutral with regard to jurisdictional claims in published maps and institutional affiliations.

\section{Affiliations}

\section{Birgit Pepin $^{1} \cdot$ Rolf Biehler ${ }^{2} \cdot$ Ghislaine Gueudet $^{3}$}

Rolf Biehler

biehler@math.upb.de

Ghislaine Gueudet

Ghislaine.gueudet.1@univ-rennes1.fr

1 Eindhoven School of Education, Eindhoven University of Technology, Eindhoven, The Netherlands

2 University of Paderborn, Paderborn, Germany

3 University of Brest, Brest, Bretagne, France 